\title{
Echocardiographic findings late after myectomy in hypertrophic obstructive cardiomyopathy
}

\author{
J. Turina*, R. Jenni*, H. P. KRayenbuehL*, M. Turina $†$ and M. Rothlin† \\ ${ }^{*}$ Medical Policlinic, Division of Cardiology and †Clinic for Cardiovascular Surgery, University Hospital, \\ Zurich, Switzerland
}

KEY WORDS: Hypertrophic obstructive cardiomyopathy, echocardiography, myectomy.

Postoperative echocardiograms of 50 patients undergoing myectomy for hypertrophic obstructive cardiomyopathy between 1965 and 1982 have been evaluated. In 21 patients a comparison with preoperative echocardiograms showed that postoperatively there was a significant reduction of septal and free wall thickness, an increase of left ventricular end-diastolic as well as outflow tract dimensions and a reduction or disappearance of systolic anterior motion of the mitral leaflet. Postoperative examination at intervals $>3$ years revealed a significant increase of left ventricular and left atrial cavity size with unchanged contractile parameters and little reduction of left ventricular hypertrophy. In 4 of 12 patients evaluated $>8$ years after myectomy, left ventricular dilatation was observed and 3 of these 4 patients developed congestive heart failure. Development of left ventricular dilatation was independent of whether a transventricular and/or transaortic approach was used for myectomy. These data indicate that the late course after myectomy in hypertrophic obstructive cardiomyopathy may be complicated by dilatation of the left ventricular cavity.

Surgical treatment of hypertrophic obstructive cardiomyopathy began in the early sixties and is today a well established therapeutic procedure for symptomatic patients with a high pressure gradient across the outflow tract of the left ventricle and severe mitral regurgitation. Different surgical procedures for relief of subaortic muscular obstruction have been used but myectomy of the hypertrophic septal myocardium is usually performed ${ }^{[1-3]}$. Despite the very encouraging results of various studies $^{[4-6]}$ some objections to surgical treatment of hypertrophic obstructive cardiomyopathy have been put forward ${ }^{[7.8]}$. These objections were raised because the late outcome may be unsatisfactory due to the development of progressive myocardial contraction disturbances resembling dilated cardiomyopathy ${ }^{[9]}$. The purpose of this study is to demonstrate echocardiographic findings after operation for hypertrophic obstructive cardiomyopathy with special emphasis on late postoperative results.

\section{Material and methods}

We have studied 50 patients with hypertrophic

Submitted for publication on 31 October 1985 and in revised form 30 January 1986.

Address for correspondence: Juraj Turina, M.D., Medical Policlinic, University Hospital, CH-8091 Zurich, Switzerland. obstructive cardiomyopathy, 34 men and 16 women, who underwent surgical resection of the hypertrophied septum (myectomy) between 1965 and 1982. The age at the time of operation was 14 to 66 years, the mean age being 37 years. All patients, except one with severe mitral regurgitation, had a resting pressure gradient across the outflow tract of the left ventricle. This gradient exceeded $50 \mathrm{mmHg}$ in 42 patients and ranged between 32 and $47 \mathrm{mmHg}$ in the other 7 patients. Before operation, 6 patients were in New York Heart Association class I, 18 in class II, 21 in class III and 5 in class IV. The indication for surgery were a resting pressure gradient more than $50 \mathrm{mmHg}$ (6 patients in New York Heart Association class I), persistent or progressive symptoms in spite of medical treatment and severe mitral regurgitation. We were able to evaluate $75 \%$ of the entire patient population operated at our institution. Echocardiography has been performed in our institution since 1974 and thus patients who died before 1974 did not have echocardiographic examinations. Postoperative medical treatment of the patients was not uniform. Twenty-two patients had no medical treatment. At the last follow-up examination 11 patients were on betablockers and 9 on verapamil. Diuretics were used in 5 patients and in 3 patients with ventricular extrasystoles amiodarone was given. 


\section{SURGICAL PROCEDURE}

All patients except one have been operated on in our hospital. Surgical techniques for septal myectomy varied: in 23 patients myectomy was performed via an apical ventriculotomy according to Senning ${ }^{[3]}$ and in 20 patients by the aortic approach; a combined transventricular and transaortic approach was used in 7 patients. Additional reconstructive procedures of the mitral valve were performed in 3 patients. Until 1976 most of the patients underwent transventricular myectomy. Since that time transaortic approach was generally used but the type of operation depended also on localization and amount of septal hypertrophy. Intraoperative myocardial protection with magnesium-asparaginate, hypothermia and pericardial irrigation was used from 1975 to 1977 and since 1978 hypothermic potassium cardioplegia and pericardial irrigation were applied.

\section{FOLLOW-UP}

The patients were followed for 1 to 19 years, mean follow-up being 7.5 years. None of the patients died during the perioperative period; 2 patients died 3 and 9 years after surgery suddenly and unexpectedly and one patient 6 years after surgery from acute heart failure. Ten-year cumulative actuarial survival was $89 \%$. Two patients underwent reoperation within 6 months of myectomy for severe aortic regurgitation and ventricular septal defect; reconstruction of aortic valve and closure of septal defect were performed. A significant improvement in New York Heart Association class from 2.5 preoperatively to 1.6 postoperatively $(P<0.01)$ was noted. Postoperative cardiac catheterization was performed at different times during the follow-up in 17 patients: 7 had no resting pressure gradient, 6 a gradient below $15 \mathrm{mmHg}$ and one patient had a gradient of $44 \mathrm{mmHg}$ (preoperative $95 \mathrm{mmHg}$ ).

\section{ECHOCARDIOGRAPHY}

All 50 patients had postoperative echocardiographic studies but only 21 also had a preoperative one. Technical quality of the echocardiograms in another 3 patients was not adequate and these patients were not included in the study. The great majority of patients had several echocardiographic studies during the follow-up period. Echocardiography was performed in the supine or slight left lateral position; electrocardiogram and phonocardiogram were recorded simultaneously. Enddiastolic left ventricular dimensions were measured at the peak of the R-wave of the electrocardiogram and the end-systolic dimensions at the beginning of the second sound of the phonocardiogram. Outflow tract dimensions were expressed as the distance between the mitral valve and the septum at the very beginning of the systole. Postoperative end-systolic dimensions and percent systolic shortening of the left ventricular diameter are not reported for all patients because two-thirds of the patients had left bundle branch block existing postoperatively. These values are presented only in the 30 patients undergoing repeated postoperative measurements where we looked for a change in systolic contractile function during the follow-up period. Presented data are the average of the measurements of 3 beats.

\section{Results}

\section{POSTOPERATIVE ECHOCARDIOGRAMS}

Figure 1 summarizes the most relevant echocardiographic data of all 50 patients. In the patients having more than one postoperative study the data of the last available echocardiogram (in the average 6.5 years after operation, range $0 \cdot 3-18$ years) are presented. For each variable the normal range in our laboratory is also depicted. The normal range is based on measurements of 50 healthy subjects 18-62 years old, 36 men and 14 women. Postoperative left ventricular end-diastolic dimensions were within normal limits in the majority of the patients; in $9 / 50(19 \%)$ left ventricular cavity size was still below the normal limit and 4 patients had clearly enlarged left ventricular dimensions. Left ventricular outflow tract dimensions were within the normal range in the majority of the patients; in $12 / 50(24 \%)$ a narrow outflow tract persisted despite myectomy. Septal hypertrophy $(>12 \mathrm{~mm}$ ) was found in all but 2 patients. Posterior wall thickness was within the normal range in $41 / 50$ $(82 \%)$ or only slightly increased; hence septum/ posterior wall ratio was $>1.3$ in the majority of the patients. Systolic anterior motion of the anterior mitral leaflet was absent postoperatively in 30 patients, 19 had only moderate systolic anterior motion not reaching the septum and only one patient had systolic anterior motion reaching the septum. This patient had a postoperative resting pressure gradient of $10 \mathrm{mmHg}$.

\section{COMPARISON BETWEEN PRE- AND POSTOPERATIVE} DATA

Preoperative ( $<1$ year before operation) and postoperative (average 2.8 years after operation, 


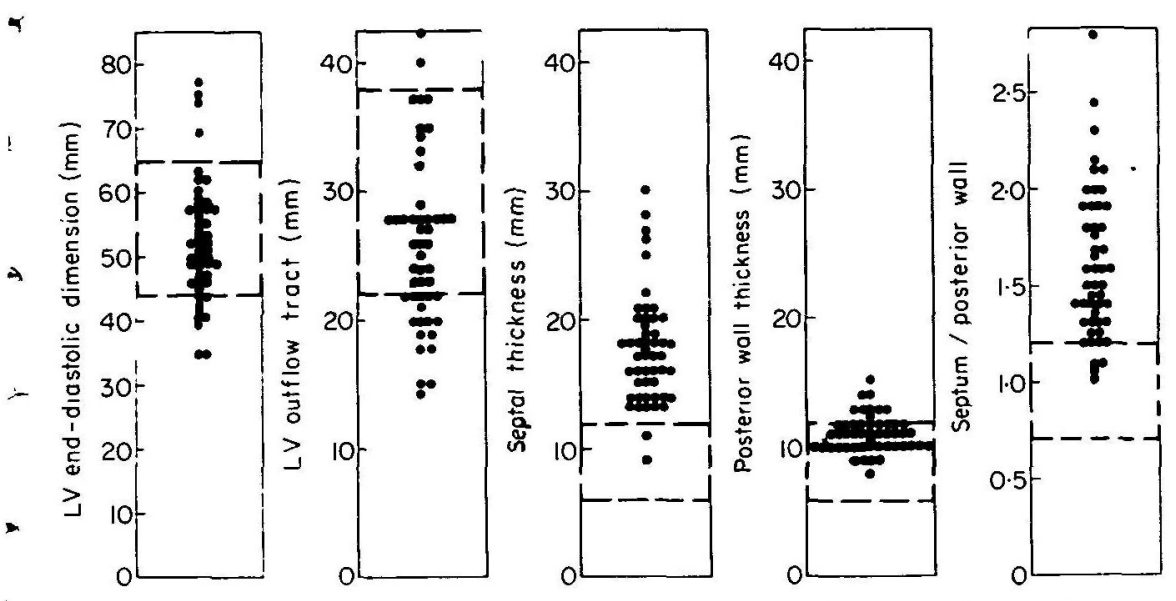

Figure 1 Data from the last postoperative echocardiogram of all 50 patients undergong myectomy. The normal range of our laboratory for each variable is given by interrupted lines (LV - left ventricle).

range $0 \cdot 3-7$ years) echocardiograms were obtained in 21 patients (Fig. 2). Postoperatively a significant increase in left ventricular end-diastolic and outflow tract dimensions as well as a reduction of septal and to a lesser degree of posterior wall thickness were found.

\section{COMPARISON BETWEEN EARLY AND LATE} POSTOPERATIVE DATA

In 30 patients postoperative echocardiograms at intervals of more than 3 years (average interval 4.6 years) were obtained. Figure 3 depicts the comparison between the first and the last postoperative echocardiogram. A significant increase of left ventricular end-diastolic and left atrial dimensions was noted; septal thickness decreased moderately but significantly; outflow tract dimensions and posterior wall thickness did not change significantly. In this group of 30 patients we have also evaluated the influence of various surgical procedures on left ventricular cavity size. The patients were divided into 2 groups according to the increase in left ventricular end-diastolic dimensions from the first to the last postoperative echocardiogram: in 16 patients this increase was at least $10 \%$ of the initial value and in 14 it was less than $10 \%$ (Table 1). Patients undergoing transventricular and transaortic as well as combined surgical approach for myectomy were equally distributed between the two groups (Table 1). Twelve patients had intraoperative myocardial protection during myectomy. These patients were equally distributed between the two groups (Table 1). In these two groups of

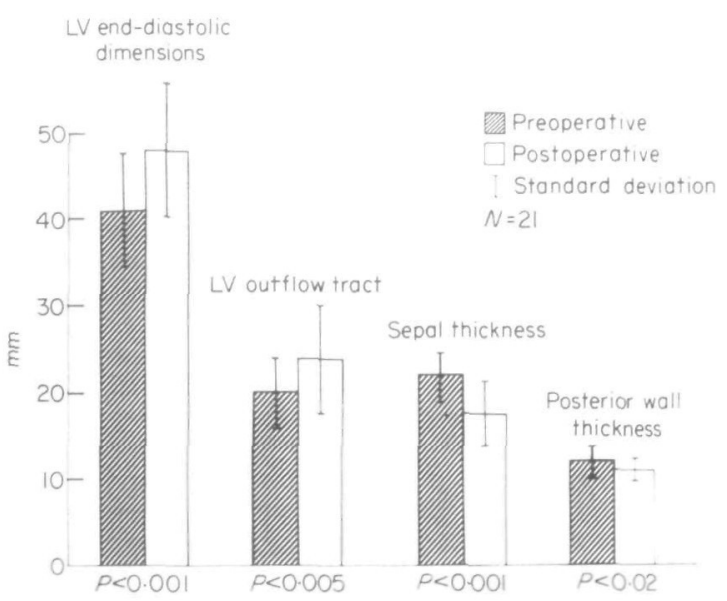

Figure 2 Comparison between pre- and postoperative echocardiographic measures of left ventricular dimensions and wall thickness in 21 patients, (LV-left ventricle, $S$ - not significant, $\mathrm{P}$ - probability).

patients the changes in percent systolic shortening of the left ventricular diameter, left atrial size and thickness of the septum and free wall from the first to the last echocardiogram were also evaluated (Table 2). A significant increase of left atrial size occurred in both groups and in all patients except one regardless of initial atrial size. Posterior wall thickness decreased slightly but significantly in the group with an increase of left ventricular enddiastolic dimension whereas the decrease of septal hypertrophy remained below the level of statistical 


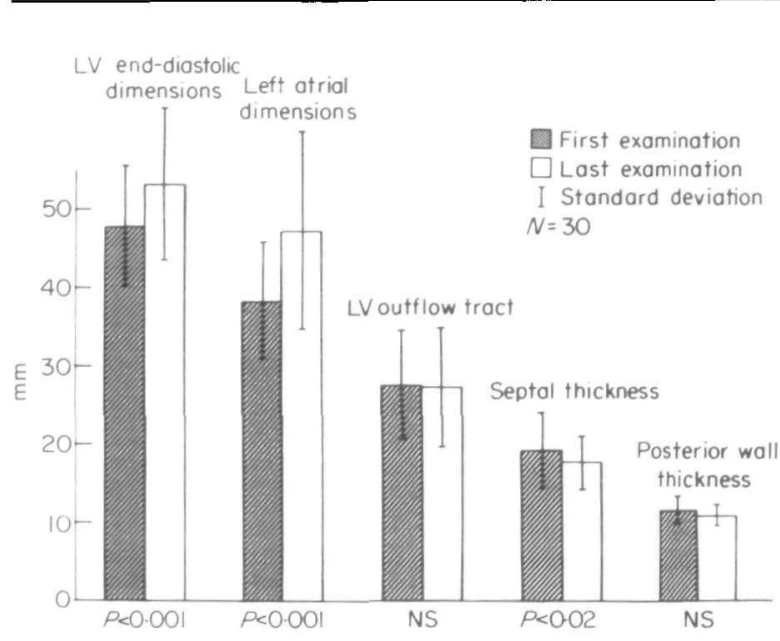

Figure 3 Comparison between the first and the last postoperative echocardiogram obtained at an interval $>3$ years. (LV - left ventricle, $\mathrm{P}$ - probability).

Table 1 Type of surgical technique for myectomy and intraoperative myocardial protection in pattents examined postoperatively in an interval of more than 3 years. The patients are divided into 2 groups according to the increase in LV enddiastolic dimensions from the first to the last echocardiogram

\begin{tabular}{lcc}
\hline & $\begin{array}{c}\text { Group 1: } \\
\text { increase } \geqslant 10 \% \\
\text { of initial value } \\
(N=16)\end{array}$ & $\begin{array}{c}\text { Group 2: } \\
\text { increase }<10 \% \\
\text { of initial value } \\
(N=14)\end{array}$ \\
\hline $\begin{array}{l}\text { Surgical technique } \\
\text { transventricular } \\
\text { transaortic } \\
\text { combined }\end{array}$ & 8 & 8 \\
$\begin{array}{l}\text { Myocardial protection } \\
\text { yes } \\
\text { no }\end{array}$ & 6 & 5 \\
\hline
\end{tabular}

significance in both groups. Systolic percent shortening of the end-diastolic diameter did not change significantly in either group.

\section{FINDINGS $>8$ YEAR AFTER OPERATION}

Fourteen patients had echocardiographic studies more than 8 years after the operation (average 11.8 years, range $8-18$ years). None of these patients underwent myectomy with myocardial protection because all of them were operated before 1974 . Four of these patients had a sizeably increased left ventricular end-diastolic dimension and were the only ones with a postoperatively increased left ventricular cavity size. The most relevant echocardiographic and clinical data of these patients are presented in Table 3 . All patients had persistent septal hypertrophy and despite left bundle branch block systolic percent shortening was decreased only in one patient with left ventricular dilatation. Two of these 4 patients were studied repeatedly over years and showed a progressive increase of left ventricular end-diastolic dimension from normal to sizeably enlarged. Three patients had symptoms of congestive heart failure, 2 of them being in New York Heart Association class III, one in class II. One patient remained asymptomatic. The three symptomatic patients showed slow progressive deterioration of their clinical condition after initial postoperative improvement. Transventricular myectomy was performed in 2 and transaortic in the other 2 patients. Mild, stable aortic regurgitation persisted in 2 and mild mitral regurgitation in one patient. The other 10 patients examined more than 8 years after operation showed no left ventricular dilatation, are in New York Heart Association class I and II and free of congestive heart failure symptoms. Preoperative New York Heart Association class, resting pressure gradient in the outflow tract as well as left ventricular end-diastolic pressure were not significantly different between patients with and without postoperative dilatation.

In the entire group of 50 patients undergoing myectomy mild aortic regurgitation was seen in another 4 patients without left ventricular dilatation 
Table 2 Changes of echocardiographic parameters in patients undergoing multiple postoperative examinations at intervals of more than 3 years. The patients are divided into 2 groups according to change in end-diastolic dimensions

\begin{tabular}{|c|c|c|c|c|c|}
\hline \multirow{2}{*}{ Examination } & \multirow{2}{*}{$\begin{array}{c}\text { End-diastolic } \\
\text { dimension (mm) }\end{array}$} & \multirow{2}{*}{$\begin{array}{l}\text { Percent systolic } \\
\text { shortening (\%) }\end{array}$} & \multirow{2}{*}{$\begin{array}{c}\text { Left atrial } \\
\text { dimension }(\mathrm{mm})\end{array}$} & \multicolumn{2}{|c|}{ Wall thickness (mm) } \\
\hline & & & & Septum & Posterior wal \\
\hline \multicolumn{6}{|c|}{ Group 1 (end-diastolic dimension increasing $\geqslant 10 \%, N=16$ ) } \\
\hline First & $\begin{array}{l}45 \cdot 7 \pm 6 \cdot 1 \\
53 \cdot 8 \pm 6 \cdot 9\end{array}$ & $\begin{array}{c}36 \cdot 0 \pm 9 \cdot 7 \\
\mathrm{NS} \\
33 \cdot 4 \pm 10 \cdot 1\end{array}$ & $\begin{array}{c}37 \cdot 5 \pm 6 \cdot 1 \\
P<0 \cdot 005 \\
46 \cdot 7 \pm 13 \cdot 5\end{array}$ & $\begin{array}{l}19 \cdot 7 \pm 5 \cdot 8 \\
N S \\
18 \cdot 0 \pm 4 \cdot 0\end{array}$ & $\begin{array}{c}11.6 \pm 1.8 \\
P<0.05 \\
10.7 \pm 0.9\end{array}$ \\
\hline
\end{tabular}

Group 2 (end-diastolic dimension increasing $<10 \%, N=14$ )

\begin{tabular}{|c|c|c|c|c|c|}
\hline First & $49 \cdot 6 \pm 9 \cdot 2$ & $\begin{array}{c}34 \cdot 2 \pm 12 \cdot 3 \\
\mathrm{NS}\end{array}$ & $\begin{array}{c}39.3 \pm 8.6 \\
P<0.001\end{array}$ & $\begin{array}{c}18.7 \pm 2.8 \\
\text { NS }\end{array}$ & $11 \cdot 7 \pm 1 \cdot 2$ \\
\hline Last & $49.6 \pm 9.6$ & $36.6 \pm 8.9$ & $48.6 \pm 13.0$ & $1 / \cdot 9 \pm 3 \cdot 4$ & $12 \cdot 0 \pm 2 \cdot 0$ \\
\hline
\end{tabular}

NS - not significant, $P$ - probability

Table 3 Clinical and echocardiographic data of 14 patients examined more than 8 years after myectomy. The patients are divided in groups with and without left ventricular dilatation. The mean value and range of each variable are given

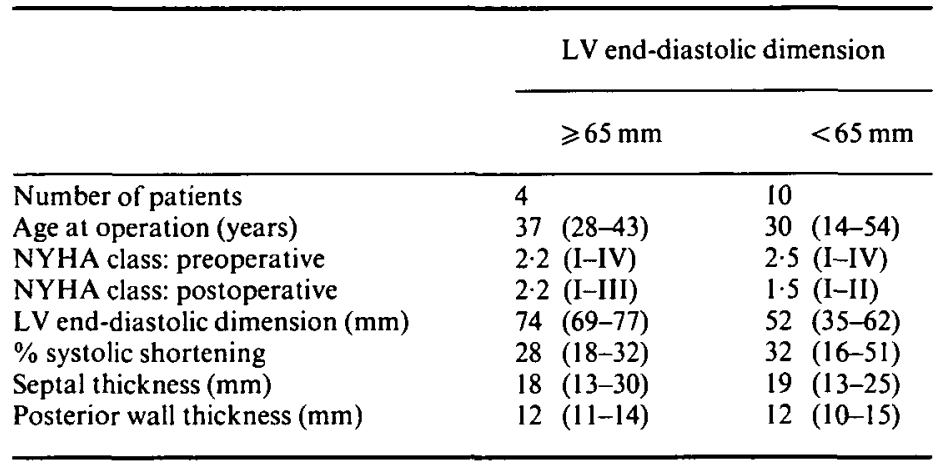

and without congestive heart failure symptoms. Conversely, congestive heart failure symptoms were found in 5 patients without left ventricular dilatation at different times after operation.

\section{Discussion}

\section{SURGICAL TREATMENT OF HYPERTROPHIC OBSTRUCTIVE CARDIOMYOPATHY}

Surgical treatment of hypertrophic obstructive cardiomyopathy in patients with a high resting pressure gradient, persisting or progressive symptoms despite medical therapy and severe mitral regurgitation is a well established therapeutic procedure ${ }^{[1.8]}$. Very encouraging results, with various surgical procedures, have been reported from several centres ${ }^{[4,11]}$. The success of operative treatment has been demonstrated by a reduction or abolition of the pressure gradient in the left ventricular outflow tract, significant symptomatic improvement and even an improvement in longterm survival has been claimed[4, 10,12]. In the experience of our clinic 10 year survival rate in surgical patients was not significantly higher than in nonsurgical ones $(80 \%$ vs. $71 \%)$ but patients were not assigned at random to surgical or medical treatment and therefore were not truly comparable. In fact patients with high resting gradients were selected for myectomy ${ }^{[5]}$. Because of many differences between patient characteristics in surgical and non-surgical cohorts any comparison remains speculative. This is one of the reasons 
why there is still scepticism concerning the value of surgical treatment in hypertrophic obstructive cardiomyopathy ${ }^{[8.9]}$.

\section{ECHOCARDIOGRAPHY AFTER MYECTOMY}

Echocardiography is the most valid non-invasive diagnostic tool in hypertrophic obstructive cardiomyopathy. The echocardiographic findings of asymmetrical septal hypertrophy, narrow left ventricular outflow tract and systolic anterior motion of the anterior mitral leaflet are cornerstones of the diagnosis of hypertrophic obstructive cardionyopathy ${ }^{[13]}$. Even a fair correlation between the extent of systolic anterior motion and the left ventricular outflow tract pressure gradient has been found ${ }^{(13)}$. Postoperatively an attenuation or disappearance of systolic anterior motion, widening of the outflow tract, increase in left ventricular dimensions and reduction of septal as well as free wall hypertrophy have been demonstrated ${ }^{[14-16}$. We obtained postoperative echocardiograms in $75 \%$ of the patients undergoing myectomy for hypertrophic obstructive cardiomyopathy at our institution. Clinical and hemodynamic data in the patients studied echocardiographically did not differ significantly from the entire patient population operated upon. Nevertheless 10 year survival in the presently evaluated group with echocardiographic examinations was slightly although not significantly higher $(89 \%)$ than in the entire group $(80 \%)$ of patients who had undergone myectomy at our institution ${ }^{[10]}$. We were able to document a significant postoperative increase of left ventricular end-diastolic and outflow tract dimensions as well as reduction of septal and free wall thickness. This increase of left ventricular dimensions and reduction of hypertrophy were more pronounced late postoperatively than early after surgery. The small decrease of wall thickness observed late postoperatively might be the consequence of a thinning effect upon the myocardium by the increase of left ventricular internal dimension. Abolition and decrease of systolic anterior motion after the operation correlated well with reduced or absent left ventricular pressure gradient in patients undergoing haemodynamic studies. All these observations correspond well with previous reports ${ }^{[4-16]}$.

Although septal myectomy in hypertrophic obstructive cardiomyopathy had beneficial effects on clinical, haemodynamic and echocardiographic findings this procedure is not a remedy but a palliation. Even after successful operation echocardiographically marked septal hypertrophy is found in a vast majority of the patients and about one quarter of them still had a narrow left ventricular cavity and reduced outflow tract dimension. Increase of left atrial size after operation suggested a persistent diastolic compliance disturbance which is independent of left ventricular cavity size.

\section{LEFT VENTRICULAR DILATATION AND CONGESTIVE} HEART FAILURE

In hypertrophic obstructive cardiomyopathy congestive heart failure death is rare and responsible for only a small minority of cardiac related deaths ${ }^{[17-19]}$. Symptoms of congestive heart failure are generally a consequence of compliance failure of a severely hypertrophied but normal sized left ventricle with intact systolic pump function ${ }^{[7]}$. Even if global heart enlargement on chest radiography ensues this is a consequence of left atrial and right heart enlargement ${ }^{[7]}$. This increase in heart size is prominent in patients with symptomatic deterioration ${ }^{[20]}$. Spontaneous transition from hypertrophic obstructive cardiomyopathy to a pattern resembling dilated cardiomyopathy and characterized by enlarged left ventricular cavity, normal left ventricular outflow tract size and reduced left ventricular contractions is extremely rare but has been documented ${ }^{[2]}$. In our institution we have seen only one such case ${ }^{[22]}$. Significant increase of left ventricular dimensions during the spontaneous course of the disease or with various medical treatments was not observed [19.23].

After operation for hypertrophic obstructive cardiomyopathy, death from heart failure is seen more often and is responsible for about half of all cardiac deaths $\mathbf{s}^{[4.6 .10]}$. In 1975 Oakley warned against surgery in hypertrophic obstructive cardiomyopathy assuming that operative myocardial damage leads to subsequent reduction of left ventricular performancel'?. At that time myocardial protection procedures were not applied during the operation. In contrast to this contention more recent reports have mentioned no important impairment of left ventricular pump function early after myotomy and myectomy ${ }^{[24.25]}$. Favourable long term results and symptomatic improvements of most patients even late after surgery are also arguments against a general worsening of global left ventricular function after operation ${ }^{[4,6.10]}$. An enlargement of the left ventricular cavity was seldom reported after operation for hypertrophic obstructive cardiomyopathy. Most cases that were noted occurred early postoperatively and were due to localized, aneurysmatal left ventricular wall abnormali- 
ties ${ }^{[2.26 .27]}$. These aneurysms were a consequence of intraoperative damage of a coronary artery[2,26]. Late postoperative left ventricular dilatation in 2 other cases was considered to be due to additional coronary artery disease ${ }^{[6]}$ and alcohol excess ${ }^{[4]}$. Ten Cate and Roelandt ${ }^{[28]}$ reported two cases which after an uneventful early postoperative course later ( 2 and 3 years respectively after operation) developed left ventricular dilatation and symptoms of congestive heart failure. In our patient group undergoing myectomy left ventricular dilatation was observed in 4 cases, at least 8 years, after surgery. All these patients had undergone surgery before myocardial protection procedures were introduced. In 3 of them left ventricular dilatation was accompanied by progressive worsening of their clinical condition and development of congestive heart failure symptoms. Despite left ventricular dilatation and symptoms of congestion a typical pattern of dilated cardiomyopathy was not present. Chamber dilatation was associated with marked septal hypertrophy and preserved systolic percent shortening of the left ventricular diameter. Although only a small number of patients developed late postoperative left ventricular dilatation a tendency to an increase of left ventricular dimensions was noted in about half of the patients studied over a longer period. This tendency to an increase of the left ventricular dimensions was influenced neither by the type of surgical approach used for myectomy nor by the use of myocardial protection procedures.

The question arises whether left ventricular dilatation following myectomy is a consequence of surgical treatment or a variant of the natural course of the disease? Substantial left ventricular dilatation late after operation for hypertrophic obstructive cardiomyopathy is rare. In 36 patients followed for between 10 and 21 years at the Mayo Clinic left ventricular dilatation was noted in only one with additional coronary artery disease and in 120 patients from the National Heart, Lung and Blood Institute with a mean follow-up of $5 \cdot 2$ years the only patient with dilatation had alcohol excess ${ }^{[4.6]}$. In our patients significant mitral and/or aortic regurgitation, coronary artery disease or alcoholism were not present. Transventricular or transaortic technique for myectomy seems to be without influence for the development of left ventricular dilatation. That the excision of a small amount of hypertrophied myocardium can lead after years of uneventful course, to profound changes in ventricular size seems unlikely but intra- operative myocardial damage, especially because modern myocardial protection procedures were not available at the time of operation, cannot be excluded. At the present time the importance of intraoperative myocardial protection procedures for long term results after myectomy cannot be determined precisely because the follow-up of these patients is still not long enough. A tendency to an increase of left ventricular dimensions after myectomy was noted regardless of the use of myocardial protection. Whether any of these patients will develop left ventricular dilatation during longer follow-up will only become apparent at least 8 to 10 years after operation. Preoperative and early postoperative clinical and haemodynamic data are not helpful for the prediction of late postoperative left ventricular dilatation. We should bear in mind that hypertrophic obstructive cardiomyopathy is a disease with obscure etiology and a large variety of clinical, haemodynamic and survival characteristics and at the present time not enough data for a definite explanation of such a rare complication as left ventricular dilatation late after myectomy are available. This problem demonstrates the need for long-term echocardiographic and if possible even haemodynamic investigations of patients with hypertrophic obstructive cardiomyopathy undergoing different therapeutic procedures. Our data point out that following myectomy even after years of uneventful course dilatation of left ventricular cavity and heart failure can ensue in certain patients. This observation underlines further the need for strict indications for surgery in hypertrophic obstructive cardiomyopathy. In our opinion the operative treatment should be reserved for patients with persisting high outflow tract gradients and symptoms despite optimal medical therapy.

\section{References}

[1] Morrow AG, Reitz BA, Epstein SE et al. Operative treatment in hypertrophic subaortic stenosis: Techniques, and the result of pre- and post-operative assessment in 83 patients. Circulation 1975; 52: 88-102.

[2] Agnew TM, Barratt-Boyes BG, Brandt PWT, Roche AHG, Lowe JB, O'Brien KP. Surgical resection in idiopathic hypertrophic subaortic stenosis with a combined approach through aorta and left ventricle. J Thorac Cardiovasc Surg 1977; 74: 307-16.

[3] Senning A. Transventricular relief of idiopathic hypertrophic suboartic stenosis. J Cardiovasc Surg 1976; 17: $371-6$.

[4] Maron BJ, Merill WH, Freier PA, Kent KM, Epstein SE, Morrow AG. Long term clinical course and symptomatic status of patients after operation for 
hypertrophic subaortic stenosis. Circulation 1978; 57 : 1205-13.

[5] Rothlin ME, Gobet D, Haberer T, Krayenbuehl HP, Turina M, Senning A. Surgical treatment versus medical treatment in HOCM. Eur Heart J 1983; 4 (Suppl F): 215-23.

[6] Beahrs MM, Tajik AJ, Seward JB, Giuliani ER, McGoon BC. Hypertrophic obstructive cardiomyopathy: 10-21 year follow-up after partial septal myectomy. Am J Cardiol 1983; 51:1160-6.

[7] Oakley CM. Hypertrophic obstructive cardiomyopathypatterns of progression. In: Ciba Foundation Symposium Study Group No 37. London: J \& A Churchill, 1971: 9-29.

[8] Goodwin JF, Oakley CM. Medical and surgical treatment of hypertrophic cardiomyopathy. Eur Heart J 1983; 4 (Suppl F): 209-14.

[9] Oakley CM. Surgical correction of ASH. Circulation 1975; 51: 951-2.

[10] Gobet DA, Rothlin ME. Postoperativer Langzeitverlauf und Operationsindikation bei Patienten mit hypertropher obstruktıver Kardiomyopathie. Schweız med Wschr 1984; 114:436-48.

[11] Cooley DA, Wukasch DC, Leachman RD. Mitral valve replacement for idiopathic hypertrophic subaortic stenosis. Results in 27 patients. J Cardiovasc Surg 1976; 17: $380-5$.

[12] Loogen F, Kuhn H, Gietzen F, Lösse B, Schulte HD, Birks W. Clinical course and prognosis of patients with typical and atypical hypertrophic obstructive and with hypertrophic non-obstructive cardiomyopathy. Eur Heart J 1983; 4 (Suppl F): 145-53.

[13] Gilbert BW, Pollick C, Adelman AG, Wigle ED. Hypertrophic cardiomyopathy: Subclassification by $M$ mode echocardiography. Am J Cardiol 1980; 45: 861-72.

[14] Shah PM, Gramiak R, Adelman AG, Wigle ED. Echocardiographic assessment of the effects of surgery'and propranolol on the dynamics of outflow obstruction in hypertrophic subaortic stenosis. Circulation 1972; 45: 516-21.

[15] Bolton MR, King JF, Polumbo RA et al. The effects of operation on the echocardiographic features of idiopathic hypertrophic subaortic stenosis. Circulation 1974; 50: 897-900.

[16] Köhler E, Neuhaus C, Thurow J et al. Klinische und echocardiographische Befunde nach operativer Behandlung der hypertrophisch obstruktiver Kardiomyopathie. Z Kardiol 1978; 67: 826-36.
[17] Shah PM, Adelman AG, Wigle ED et al. The natural (and unnatural) history of hypertrophic obstructive cardiomyopathy. Circ Res 1974; 34, 35 (Suppl II): 179-95.

[18] McKenna W, Deanfield J, Faruqui A, England D, Oakley C, Goodwin J. Prognosis in hypertrophic cardiomyopathy: Role of age and clinical, echocardiographic and hemodynamic features. Am J Cardiol 1981; 47: 532-8.

[19] Haberer T, Hess OM, Jenni R, Krayenbuehl HP. Hypertrophe obstruktive Kardiomyopathie: Spontanverlauf im Vergleich zur Langzeittherapie mit Propranolol und Verapamil. Z Kardiol 1983; 72: 487-93.

[20] Swan DA, Bell B, Oakley CM, Goodwin J. Analysis of symptomatic course and prognosis and treatment of hypertrophic obstructive cardiomyopathy. Br Heart J 1971; 33: 671-7.

[21] Beder SD, Gutgesell HP, Mullins CE, McNamara DG. Progression from hypertrophic obstructive cardiomyopathy to a congestive cardiomyopathy in a child. Am Heart J 1982; 104: 155-6.

[22] Hess OM, Schneider J, Gloor HO, Lütolf UM, Keiser G. Kongestive, hypertrophe Kardiomyopathie-Intermediärform der primären Herzmuskelerkrankung? $\mathbf{Z}$ Kardiol 1977; 66: 95-8.

[23] Shapiro LM, Zezulka A, Perrins EJ. Longitudinal changes in left ventricular diastolic function in hypertrophic cardiomyopathy. Int J Cardiol 1985; 8: 261-8.

[24] Borer JS, Bacharach SL, Green MV et al. Effect of septal myotomy and myectomy on left ventricular systolic function at rest and during exercise in patients with IHSS. Circulation 1979; 60 (Suppl I): 82-7.

[25] Krajcer Z, Lufschanowski R, Angelini P, Leachman $\mathrm{RD}$, Cooley DA. Septal myomectomy and mitral valve replacement for idiopathic hypertrophic subaortic stenosis. Circulation 1980; 62 (Suppl I): 158-64.

[26] Wychulis AR, Frye RL, Kincaid OW, Ongley P.A, Ellis FH. Postventriculotomy aneurysm in patients with idiopathic hypertrophic subaortic stenosis. Am J Cardiol 1971; 27: 322-6.

[27] Wiegand V, Neuhaus KL, Kreuzer H. Postoperative Dilatation des linken Ventrikels bei hypertropher obstruktiver Kardiomyopathie. Z Kardiol 1982; 71: 323-5.

[28] Ten Cate FJ, Roelandt J. Progression to left ventricular dilatation in patients with hypertrophic obstructive cardiomyopathy. Am Heart J 1979; 97: 762-4. 